\title{
Safety of blood and components obtained from voluntary and replacement donors: a comparative analysis.
}

\author{
Dr. Seema Acharya, ${ }^{1}$ Dr. Rajnish Kumar ${ }^{2}$, Dr. Sandip Kudesia ${ }^{3}$ \\ ${ }^{1,2,3}$ (Shri Guru Ram Rai Institute of Medical and Health Sciences, Dehradun, India)
}

\begin{abstract}
A eight and half year retrospective study from January, 2005 to June, 2013 was conducted in the blood bank of Shri Mahant Indiresh Hospital under the department of pathology of Shri Guru Ram Rai Institute of Medical and Health Sciences, Dehradun, Uttarakhand, India. Donors were screened for seroprevalence of $H I V, H B V, H C V$ and Syphilis. The sera of total 12716 donors were tested, out of these 6592(51.8\%) were from voluntary while 6124(48.2\%) were towards replacement donors. The incidence of HIV was $0.17 \%$ in total donors, more in replacement (0.12\%) as compared to voluntary (0.05\%). The seroprevalence of HBsAg in total donors was $0.72 \%$. Comparable results were seen in both types of donors. The seropositivity for anti HCV was $(0.55 \%)$ and was found to be higher in replacement donors $(0.43 \%)$. The seroprevalence of VDRL was $0.50 \%$ in total donors, more in replacement donors $(0.35 \%)$ as compared to voluntary donors $(0.15 \%)$. Hence, it was concluded that voluntary donation is safer than replacement donation.
\end{abstract}

Keywords: Replacement, Seropositivity, Voluntary,

\section{Introduction}

Blood/ component transfusion is a life saving modality in modern medical practice but is wrought with associated complications which are seen in $1 \%$ of all transfusions [1]. These also include the most dreaded, risk of acquiring transfusion transmitted infections.

Proper screening of donors by taking detailed history, conducting thorough physical examination and screening of donated blood for transfusion transmitted infections have considerably reduced the transmission of diseases. However, the risk of transfusion transmissible infections(TTI) still remains in developing countries due to a variety of reasons. Inability of available tests to detect the pre- seroconversion phase, immunosilent carriers, immunologic variants of virus or inadvertent testing errors by laboratory may be some of the reasons.

Despite efforts by government and non government organizations to increase public awareness, voluntary blood donation is still not the norm in India.

World over the risk of TTI using voluntary donated blood is much less than that associated with replacement donation $[2,3,4]$. Very often replacement donations are made under stress where the donor may conceal his/her past medical history.

We conducted a retrospective study at the blood bank of a tertiary care hospital attached to a medical college to find out the prevalence of voluntary and replacement donation a well as the seropositivity of the blood for Human Immunodeficiency virus (HIV), Hepatitis B virus (HBV), Hepatitis C Virus (HCV) and syphilis in these donations.

\section{Material And Method}

This retrospective study included 12716 blood donations from January 2005 to June 2013 at the blood bank of Shri Mahant Indiresh Hospital, which is a tertiary care hospital attached to Shri Guru Ram Rai institute of Medical and Health sciences Dehradun, Uttarakhand, India. Blood donors were either replacement or voluntary (walk in individuals and through holding voluntary blood donation camps).

All the 12716 sera were screened for malarial parasite, HBsAg, HIV-I and II, HCV and VDRL reactivity. The screening for HIV, HBsAg and Anti HCV were performed by ELISA using $4^{\text {th }}$ generation Microlisa HIV Antigen and Antibodies, Hepalisa and $3^{\text {rd }}$ generation HCV Microlisa manufactured by J Mitra. Testing for syphilis and malaria antigen were done by immunochromatographic method. All reactive samples were run in duplicate to confirm seropositivity.

\section{Results}

Of the 12716 donations $6592(51.8 \%$ ) were voluntary while 6124(48.2\%) were towards replacement of issued blood/products. It was also noted that there was a steady increase in percentage of voluntary donations since 2008 from $8.7 \%$ to $93.7 \%$ in 2013 till date. This commendable and significant change was seen due to a change in the policy of the management and untiring efforts of the blood bank staff to motivate people and organize blood donation camps. 
Seropositivity assessed for HIV, HBsAg, HCV and Syphilis were 22(0.17\%), 92(0.72\%) 70(0.55\%), and 64(0.50\%) respectively. "Table 1 "

Table 1: Showing relative percentages of seropositivity in voluntary and replacement donations for HIV, HCV, HBsAg and syphilis

\begin{tabular}{|l|l|l|l|}
\hline Sera screened for & Replacement Donations & Voluntary Donations & Total Seropositivity \\
\hline HIV & $0.12 \%$ & $0.05 \%$ & $0.17 \%$ \\
\hline HCV & $0.43 \%$ & $0.12 \%$ & $0.55 \%$ \\
\hline HBsAg & $0.35 \%$ & $0.37 \%$ & $0.72 \%$ \\
\hline Syphilis & $0.35 \%$ & $0.15 \%$ & $0.50 \%$ \\
\hline
\end{tabular}

Of all the 248 seropositive donations 88(35.4\%) were voluntary while 160 (64.6\%) were replacement. No significant difference in incidence of seropositivity for HBsAg was seen in voluntary donors 48 cases(52.1\%)) as compared to replacement donors 44 cases(47.9\%) while screening tests for HCV,HIV and syphilis revealed a greater seroprevalence in replacement donors. "Table 2"

Table2- Yearly distribution of seroprevalence in voluntary and replacement donation

\begin{tabular}{|c|c|c|c|c|c|c|c|c|c|c|c|}
\hline Year & $\begin{array}{c}\text { Vol. } \\
\text { donor }\end{array}$ & $\begin{array}{c}\text { Repl } \\
\text { donor }\end{array}$ & $\begin{array}{c}\text { HIV } \\
\text { Vol } \\
\text { donor }\end{array}$ & $\begin{array}{c}\text { HIV } \\
\text { Repl } \\
\text { donor }\end{array}$ & $\begin{array}{c}\text { HBsAg } \\
\text { Vol } \\
\text { donor }\end{array}$ & $\begin{array}{c}\text { HBsAg } \\
\text { Repl } \\
\text { donor }\end{array}$ & $\begin{array}{c}\text { HCV } \\
\text { Vol } \\
\text { donor }\end{array}$ & $\begin{array}{c}\text { HCV } \\
\text { Repl } \\
\text { donor }\end{array}$ & $\begin{array}{c}\text { Syphilis } \\
\text { Vol } \\
\text { donor }\end{array}$ & $\begin{array}{c}\text { Syphilis } \\
\text { Repl } \\
\text { donor }\end{array}$ & Total \\
\hline 2005 & 183 & 773 & - & 1 & 2 & 3 & - & 1 & - & 2 & 9 \\
\hline 2006 & 145 & 992 & - & 3 & - & 4 & 2 & 17 & - & 1 & 27 \\
\hline 2007 & 135 & 1360 & - & 5 & 1 & 9 & 2 & 25 & - & 1 & 43 \\
\hline 2008 & 100 & 1046 & - & 2 & - & 14 & 1 & 5 & - & 1 & 23 \\
\hline 2009 & 222 & 563 & - & 1 & 2 & 6 & - & 1 & - & 8 & 18 \\
\hline 2010 & 228 & 137 & 1 & 1 & 5 & 3 & 2 & 1 & 3 & 5 & 21 \\
\hline 2011 & 1157 & 428 & - & 2 & 3 & 3 & - & 1 & 2 & 4 & 15 \\
\hline 2012 & 2639 & 706 & 3 & - & 19 & 2 & 2 & 2 & 9 & 23 & 60 \\
\hline 2013 & 1783 & 119 & 2 & 1 & 16 & - & 6 & 2 & 5 & - & 32 \\
\hline Total & 6592 & 6124 & 06 & 16 & 48 & 44 & 15 & 55 & 19 & 45 & 248 \\
\hline
\end{tabular}

As is evident from tables $\mathbf{3} \boldsymbol{\&} \mathbf{4}$ the incidence of total seropositivity for TTI does not show any significant trend despite a definite increase in voluntary donation. However the contribution of replacement donation towards seropositive cases was higher than voluntary donation.

Table 3 Yearly distribution of voluntary and replacement donation (Figures in parenthesis indicate percentage)

\begin{tabular}{|c|c|c|}
\hline Year & Voluntary Donations & Replacement Donations \\
\hline 2005 & $183(23.6)$ & $773(76.4)$ \\
\hline 2006 & $145(12.7)$ & $992(87.3)$ \\
\hline 2007 & $135(9.03)$ & $1360(89.97)$ \\
\hline 2008 & $100(8.7)$ & $1046(91.3)$ \\
\hline 2009 & $222(28.2)$ & $785(71.8)$ \\
\hline 2010 & $228(62.4)$ & $365(37.6)$ \\
\hline 2011 & $1157(72.9)$ & $428(27.1)$ \\
\hline 2012 & $2639(78.8)$ & $3345(21.2)$ \\
\hline 2013 till June & $1783(93.7)$ & $1902(6.3)$ \\
\hline
\end{tabular}


Table 4 : Yearly distribution of percentage of voluntary and replacement donation showing seropositivity

\begin{tabular}{|c|c|c|c|c|c|}
\hline Year & $\begin{array}{c}\text { Voluntary } \\
\text { donation }\end{array}$ & $\begin{array}{c}\text { Replacement } \\
\text { donation }\end{array}$ & Total donation & $\begin{array}{c}\text { Percentage of } \\
\text { Seropositivity in } \\
\text { voluntary } \\
\text { donation }\end{array}$ & $\begin{array}{c}\text { Percentage } \\
\text { Seropositivity in } \\
\text { replacement } \\
\text { donation }\end{array}$ \\
\hline 2005 & 183 & 773 & 956 & 1.0 & 0.9 \\
\hline 2006 & 145 & 992 & 1137 & 1.3 & 2.5 \\
\hline 2007 & 135 & 1360 & 1495 & 2.2 & 2.9 \\
\hline 2008 & 100 & 1046 & 1146 & 1 & 2.1 \\
\hline 2009 & 222 & 563 & 785 & 0.9 & 7.2 \\
\hline 2010 & 228 & 137 & 365 & 4.8 & 2.3 \\
\hline 2011 & 1157 & 428 & 1585 & 0.4 & 3.8 \\
\hline 2012 & 2639 & 706 & 3345 & 1.2 & 2.5 \\
\hline $\begin{array}{c}2013 \text { Till } \\
\text { June }\end{array}$ & 1783 & 119 & 1902 & 1.5 & \\
\hline
\end{tabular}

\section{Discussion}

Transfusion of blood and blood components, though a life saving procedure does have a risk of TTI, albeit very small. Hence, the need for judicious use of transfusion cannot be overemphasized. Whereas, replacement donors constitute the largest group of donors in India as is seen by various studies, in our institute, there has been a marked increase in voluntary donations since 2010[2,3,4].(Table2) Thus an increase in public awareness and organization of voluntary blood donation camps does result in increased voluntary donations.

In our study we found an overall seroprevalence for HIV,HBsAg, HCV and syphilis as $1.9 \%$ (248 cases) which was similar to other studies[5,6]. Posititivity for HBsAg was noted in $0.72 \%$ of donor samples in our study of which $0.35 \%$ were from replacement donations and $0.37 \%$ from voluntary donations . A study conducted by -Gulia et al in the year 2011 also showed no significant difference in prevalence of seropositivity of HBsAg between voluntary and replacement donors $(2.45 \%$ vs. $2.54 \%)$ and overall prevalence of $\mathrm{HBsAg}$ infection among donors was found to be 2.48\% [5]. Singh K et al. in 2009 found a seropositivityof $0.62 \%$ for HBsAg[7] . Prevalence of HIV and VDRL seropositivity was assessed as $0.17 \%$ and $0.5 \%$ respectively, lower than the incidence found by Singh B et al. in 2005 from UCMS, Delhi [8]. They found percentage of seropositivity for HIV and Syphilis as $0.54 \%$ and $2.6 \%$ respectively. This could be attributed to a higher percentage of replacement donations $(82.4 \%)$ in their study.

Anti $\mathrm{HCV}$ antibodies were found in $0.55 \%$ of blood donors in our study which was comparable with the findings of $0.44 \%$ by Thakral et al. in 2005[9]. Voluntary donations in our study too showed a lower seropositivity for $\mathrm{HCV}(0.16 \%)$ as against $0.39 \%$ of replacement donation. This is in concordance with other studies[10] .

\section{Conclusion}

The incidence of seropositivity of donated blood for TTI in our study is comparable to other studies conducted in India. We found that percentage of seropositivity was higher in replacement donations as compared to voluntary donations for HIV, HCV and Syphilis while no significant difference was noted in seropositivity for HBsAg in the two groups.

Efforts in organizing camps and increasing public awareness made by management and blood bank staff of our institute resulted in a definite increase in voluntary donations. We anticipate these measures when implemented by other institutions/blood banks would go a long way in decreasing risk of TTI and ensuring safer blood transfusion.

\section{Acknowledgement}

We acknowledge Mr Vinod Thapliyal (Chief Technician blood bank- Shri Mahant Indiresh Hospital ,Dehradun) for his help in finalizing this manuscript.

\section{REFERENCES}

[1] Arora D, Arora B, Khetarpal A. Seroprevalence of HIV, HBV, HCV and syphilis in blood donors in Southern Haryana. Indian J Pathol Microbiol. 2010;53:308-309.

[2] Singh B, Kataria SP, Gupta, R. Infectious markers in blood donors of East Delhi: prevalence and trends. Indian J Pathol Microbiol 2004;47:477-9.

[3] Makroo RN, Salil P, Vashist RP, Lal S.Trends of HIV infection in blood donors of Delhi. Indian J Pathol Microbiol 1996;39:13942 .

[4] Sabharwal ER,LangerS. Prevalence and trends of seroprevalence of HIV and syphilis in blood donors of Delhi. Indian Journal of Practising Doctor; 2008:5(3) 
[5] Gulia SP, PandaS, Sitaramam E, Reddy KP. Seroprevalence Of Hepatitis B Virus Infection Among Blood Donors In Local Population. The Internet Journal of Pathology; $2011: 12(1)$.

[6] Bhattacharya P, Chakraborty S, Basu SK. Significant increase in HBV, HCV, HIV and syphilis infections among blood donors in West Bengal, Eastern India 2004-2005. Exploratory screening reveals high frequency of occult HBV infection. World J Gastroenterol. 2007;13:3730-3733.

[7] Singh K, BhatS, Shastry S. Trend in seroprevalence of Hepatitis B virus infection among blood donors of coastal Karnataka. India . J Infect Dev Ctries . $2009 ; 3(5): 376-9$

[8] Singh B, Verma M, Kotru M, Verma K, Batra M. Prevalence of HIV and VDRL seropositivity in blood donors of Delhi. Indian J Med Res 2005 sep; 122(3) : 234-6

[9] Thakral B, Marwaha N , Chawla YK, Saluja K, Sharma A,. Sharma RR, Minz R W ,. Agnihotri SK. Prevalence \& significance of hepatitis C virus (HCV) seropositivity in blood donors. Indian J Med Res. 2006;124: pp 431-8

[10] Garg S, Mathur DR, Garg DK, 2001. Comparison of seropositivity of HIV, HBV, HCV and syphilis in replacement and voluntary blood donors in western India. Indian Journal of Pathology and Microbiology, 44(4): 409-412. 